\title{
Uvulopalatopharyngoplasty in severe idiopathic obstructive sleep apnoea syndrome
}

\author{
ELIZABETH B WALKER, RICHARD W FRITH, DENIS A HARDING, BARRY R CANT \\ From the Department of Clinical Neurophysiology, Auckland Hospital, and the Department of Otolaryngology, \\ Green Lane Hospital, Auckland, New Zealand
}

ABSTRACT Eleven patients with severe obstructive sleep apnoea syndrome, which was fully reversed by treatment with nasal continuous positive airways pressure, underwent uvulopalatopharyngoplasty. All patients were followed for at least 12 months after surgery. One patient with large tonsils was cured. Of the remaining 10 patients, two showed minimal objective improvement at 12 months and the rest were unchanged. Four patients subsequently developed cardiac failure due to obstructive sleep apnoea. Thus uvulopalatopharyngoplasty was not effective in these patients with severe idiopathic obstructive sleep apnoea syndrome.

\section{Introduction}

Uvulopalatopharyngoplasty was first described as a surgical treatment for snoring and for the obstructive sleep apnoea syndrome in 1981. ' Subsequent studies of this form of surgery in patients with obstructive sleep apnoea syndrome ${ }^{2-13}$ have suggested a successful outcome in $23-75 \%$ of patients. Only a few patients, however, have received objective postoperative evaluation and systematic long term follow up; none of the studies has compared the relative efficacy of uvulopalatopharyngoplasty with other accepted forms of treatment and none has clearly identified factors that will predict a good outcome from surgery. Nasal continuous positive airways pressure is an effective treatment for obstructive sleep apnoea syndrome. ${ }^{14} 15$ This study tested the effectiveness of uvulopalatopharyngoplasty in patients with severe obstructive sleep apnoea syndrome whose disease had been temporarily reversed by nasal continuous positive airways pressure. All patients were followed for at least 12 months after surgery.

\section{Methods}

Consecutive patients referred to the department with a clinical diagnosis of severe obstructive sleep apnoea syndrome (severe excessive daytime sleepiness and

Address for reprint requests: Dr R W Frith, Department of Clinical Neurophysiology, Auckland Hospital, Auckland, New Zealand.

Accepted 22 December 1988 apnoea index $>35$ or minimum oxygen saturation $<75 \%$ or cardiac failure or polycythaemia), confirmed by overnight polysomnography, were entered into the study. The electroencephalogram, electrooculogram, electrocardiogram, nasal and oral airflow (thermocouples), chest and abdominal movements, and suprasternal retraction (respiratory and surface inductive plethysmography) were recorded by a Mingograf 16 channel electroencephalograph (SiemensElena). Arterial oxygen saturation was measured by ear oximeter (Hewlett-Packard 47201A). Recordings were scored and episodes of apnoea were identified on the basis of standard criteria. ${ }^{16}{ }^{17}$ Patients with obstructive sleep apnoea not satisfying the above criteria and those who had retrognathia were excluded. Preoperative assessment included an examination by an otolaryngologist, haematology profile, respiratory function tests, and computed tomography of the upper airway. Informed consent was obtained from each patient and the study was approved by the Auckland Hospital Board ethical committee.

Treatment with nasal continuous positive airways pressure was started, using standard methods for this department, ${ }^{15}$ and in each subject repeat overnight studies showed abolition of obstructive sleep apnoea syndrome (no clinical symptoms attributable to the syndrome, apnoea index $<5$, minimum oxygen saturation $>90 \%$ ). After withdrawal of nasal continuous positive airways pressure for a minimum of one week the obstructive sleep apnoea was shown by polysomnography to have returned to its previous severity in all cases. 
Uvulopalatopharyngoplasty was performed by one otolaryngologist (DH), who used a standard procedure. ${ }^{18}$ Under general anaesthesia tonsillectomy was performed if tonsillar tissue was present. The strip of palatal tissue to be excised was marked on the anterior pillars and free edge of the soft palate, including the uvula, usually $1 \mathrm{~cm}$ from the palatal margin. Sufficient tissue was removed to produce moderate tension when the soft palate was sutured to the cut edges of the tonsillar pillars. A small amount of tissue was also resected from the posterior pillars on each side. The cut edges were opposed with absorbable interrupted sutures. In three patients nasal septoplasty was performed to correct partial nasal obstruction due to deviation of the nasal septum.

All patients underwent clinical assessment and polysomnography three and 12 months after surgery. Nasal continuous positive airways pressure was offered to each patient when the 12 month postoperative study showed return of severe obstructive sleep apnoea syndrome. One patient in whom nasal continuous positive airways pressure had been restarted before the 12 month assessment had it withdrawn for one week before the overnight study.

\section{Results}

Eleven patients satisfied the selection criteria. All patients had severe daytime sleepiness sufficient to produce major disruption of daily life. All snored and had repeated apnoeic attacks observed by their sleeping partners. Hypertension was present in seven, congestive cardiac failure in three, and polycythaemia in three. All but one were obese. Other characteristics of the patients and the results of preoperative polysomnography are shown in the table. Computed tomography in nine patients showed narrowing confined to the level of the oropharynx; two patients (Nos 1 and 8 ) could not be scanned because of gross obesity.
Nine patients had abnormal results in respiratory. function tests, two had a minor increase in airways resistance reversed by a bronchodilator, and the remainder had a reduction in lung volumes consistente with obesity.

Nasal continuous positive airways pressure had been used by the patients before surgery for periods 0 ranging from three weeks to 30 months (mean 7.30 months). This had produced clinical and polysomno- $\overrightarrow{0}$ graphic evidence of complete reversal of obstructivesleep apnoea syndrome in all patients.

There were no major postoperative complications? of uvulopalatopharyngoplasty, although all patientsx experienced pain on swallowing for one to two weeks $\vec{A}$ Nasal escape of air while talking was a commoniw problem and persisted for months in some patients. $N$

The results of polysomnography three and $12 \mathrm{~N}$ months after surgery are summarised in the table. Af three months patient 1 , who before operation had substantial tonsillar enlargement, was cured. Two others (patients 3 and 10 ) showed a reduction in thes apnoea index but the polysomnographic abnormalities were still severe. In one (patient 3) theo improvement was associated with a weight loss of $18.5 \mathrm{~kg}$. All but one patient reported a reduction in daytime sleepiness at three months. The spouses reported a major reduction in the loudness of snoringo but soft inspiratory snoring persisted in all cases. Iñ patient 2 , who remained in congestive cardiac failure $\stackrel{\mathbb{Q}}{\mathscr{Q}}$ nasal continuous positive airways pressure was $\mathrm{re} \overrightarrow{\vec{\theta}}$ started at this stage.

Twelve months after surgery patient 1 was symptom? free with a normal polysomnogram, although she remained grossly overweight. Patient 3 had main tained his weight loss with subjective improvement, but frequent episodes of apnoea and oxygen desatura $\ddot{x}$ tion persisted and because of congestive cardiac failurę nasal continuous positive airways pressure was restar ted. Patient 9 maintained mild improvement in theo

Patients' characteristics and polysomnographic findings before uvulopalatopharyngoplasty and at follow up

\begin{tabular}{|c|c|c|c|c|c|c|c|c|c|c|c|c|c|}
\hline \multirow[b]{2}{*}{$\begin{array}{l}\text { Patient } \\
\text { No }\end{array}$} & \multirow[b]{2}{*}{$\begin{array}{l}\text { Sex, } \\
\text { age }(y)\end{array}$} & \multicolumn{4}{|c|}{ Before operation } & \multicolumn{4}{|c|}{3 months after operation } & \multicolumn{4}{|c|}{12 months after operation } \\
\hline & & $\begin{array}{l}W t \\
(k g)\end{array}$ & $A I$ & $\begin{array}{l}\text { O, Desat } \\
(\% \text { fall })\end{array}$ & $\begin{array}{l}\operatorname{Min} O_{2} \\
\text { Sat }(\%)\end{array}$ & $\begin{array}{l}W t \\
(k g)\end{array}$ & $A I$ & $\begin{array}{l}\text { O, Desat } \\
\text { (\% fall })\end{array}$ & $\begin{array}{l}\operatorname{Min} O_{2} \\
\text { Sat }(\%)\end{array}$ & $\begin{array}{l}W t \\
(k g)\end{array}$ & $A I$ & $\begin{array}{l}\mathrm{O}_{2} \text { Desat } \\
(\% \text { fall })\end{array}$ & $\begin{array}{l}\operatorname{Min} \mathrm{O}_{2} \\
\text { Sat }(\%)\end{array}$ \\
\hline 1 & F 23 & 169 & 85 & 14 & 45 & 164 & 0 & 0 & 89 & 161 & 0 & 0 & 90 \\
\hline 2 & M 29 & 58 & 55 & 14 & 35 & - & 50 & 13 & 28 & 55 & 55 & 15 & 26 \\
\hline 3 & M 45 & 108 & 91 & 11 & 48 & 85 & 56 & 13 & 56 & 94 & 53 & 11 & 62 \\
\hline 4 & M 41 & 126 & 70 & 25 & 31 & 126 & 61 & 17 & 49 & 127 & 73 & 26 & 38 \\
\hline 5 & M 51 & 126 & 42 & 11 & 45 & 116 & 36 & 9 & 51 & 117 & 47 & 14 & 43 \\
\hline 6 & M 48 & 116 & 56 & 21 & 52 & 115 & 56 & 20 & 54 & 122 & 57 & 23 & 44 \\
\hline 7 & M 43 & 107 & 37 & 7 & 72 & 109 & 88 & 8 & 81 & 112 & 54 & 11 & 77 \\
\hline 8 & M 26 & 155 & 66 & 13 & 27 & 153 & 72 & 12 & 59 & 161 & 83 & 13 & 61 \\
\hline 9 & M 44 & 113 & 98 & 8 & 75 & 107 & 82 & 6 & 81 & 113 & 76 & 6 & 77 \\
\hline 10 & M 47 & 98 & 124 & 10 & 36 & - & 59 & 7 & 64 & 101 & 112 & 10 & 40 \\
\hline 11 & M 26 & 105 & 49 & 7 & 84 & 101 & 32 & 5 & 89 & 102 & 51 & 6 & 83 \\
\hline
\end{tabular}

AI-apnoea index (mean number of episodes of obstructive apnoea or hypopnoea/hour); $\mathrm{O}_{2}$ Desat--mean oxygen desaturation per episode of apnoea or hypopnoea; Min $\mathrm{O}_{2}$ Sat-minimum oxygen saturation during sleep; Wt-weight. 
apnoea index and in the degree of oxygen desaturation, although he still had severe obstructive sleep apnoea syndrome. Nasal continuous positive airways pressure was restarted for five patients. The remainder declined further treatment; two of them (patients 5 and 6) developed congestive cardiac failure and one (patient 5) died in his sleep.

\section{Discussion}

This prospective study of surgical intervention in obstructive sleep apnoea syndrome was confined to a small group of patients with severe disease because they required definitive long term treatment. Previous reports have provided conflicting data about the role of uvulopalatopharyngoplasty in such patients. If successful, uvulopalatopharyngoplasty would avoid the complications of tracheostomy ${ }^{2021}$ and difficulties of compliance with long term nasal continuous positive airways pressure. ${ }^{15}$ Our results show a uniformly bad outcome after uvulopalatopharyngoplasty in these patients with severe idiopathic obstructive sleep apnoea syndrome. The only patient cured in this series did not have the idiopathic syndrome as she had very large tonsils that almost occluded the pharynx, and tonsillectomy alone might have been the treatment of choice. ${ }^{22}$ Another patient who showed sustained improvement in polysomnographic indices had weight loss, which on its own might have been expected to produce the observed change. ${ }^{23}$ One explanation for early improvement in some studies may be weight loss due to postoperative dysphagia.

Several factors could have contributed to the bad outcome after surgery. Morbid obesity has been correlated with poor results of surgery ${ }^{4}$ and in some series grossly obese patients with appreciable oxygen desaturation during sleep have been excluded. ${ }^{5}$ Others, however, have found that low body weight predicts poor outcome. ${ }^{8}$ Narrowing of the airway at more than one level has been associated with failure of uvulopalatopharyngoplasty in some patients. ${ }^{6811}$ Computed tomography, however, showed that narrowing was confined to the oropharynx in the nine patients examined with this technique. Failure to respond to surgery has also been attributed to removal of insufficient tissue at surgery, ${ }^{24}$ but surgery was considered to be satisfactory in all patients in this group.

Prominent reduction in the loudness of snoring was noted by all the spouses interviewed. This led to the erroneous impression on the part of the patient and family that the patient's disease had improved. This was a major factor in poor compliance with nasal continuous positive airways pressure even after the poor results of surgery had been explained to the patient or major complications had developed. The reason for symptomatic improvement of obstructive sleep apnoea syndrome despite persistence of severe abnormalities as shown by polysomnography after uvulopalatopharyngoplasty is not clear, but this subjective improvement also contributed to the reluctance of some patients to restart nasal continuous positive airways pressure.

All of our patients were cured by nasal continuous positive airways pressure; tracheostomy would have been an effective alternative treatment. The failure of uvulopalatopharyngoplasty in these patients with severe idiopathic obstructive sleep apnoea syndrome shows that caution should be exercised in considering this form of treatment for similar patients.

This work was supported by the Auckland Medical Research Foundation. We thank Angella Ireland and Nigel Shaw for assistance in the preparation of this manuscript.

\section{References}

1 Fujita S, Conway W, Zorick F, Roth T. Surgical corrections of anatomic abnormalities in obstructive sleep apnea syndrome: uvulopalatopharyngoplasty. Otolaryngol Head Neck Surg 1981;89:923-34.

2 Hernandez SF. Palatopharyngoplasty for the obstructive sleep apnea syndrome: technique and preliminary report of results in ten patients. Am J Otolaryngol 1982;3:229-34.

3 Borowiecki B de B, Sassin JF. Surgical treatment of sleep apnea. Arch Otolaryngol 1983;109:508-12.

4 Simmons FB, Guilleminault C, Silvestri R. Snoring, and some obstructive sleep apnea, can be cured by oropharyngeal surgery-palatopharyngoplasty. Arch Otolaryngol 1983;109:503-7.

5 Guilleminault C, Hayes B, Smith L, Simmons FB. Palatopharyngoplasty and obstructive sleep apnea syndrome. Bull Euro Physiopathol Respir 1983;19: 595-9.

6 Fujita S. UPPP for sleep apnea and snoring. Ear Nose and Throat Journal 1984;63:227-35.

7 Simmons FB, Guilleminault C, Miles LE. The palatopharyngoplasty operation for snoring and sleep apnea: an interim report. Otolaryngol Head Neck Surg 1984; 92:375-80.

8 Fujita S, Conway WA, Zorick FJ, et al. Evaluation of the effectiveness of uvulopalatopharyngoplasty. Laryngoscope 1985;95:70-4.

9 Conway W, Fujita S, Zorick F, et al. Uvulopalatopharyngoplasty: one year follow-up. Chest 1985;88: 385-7.

10 Wetmore SJ, Scrima L, Snyderman NL, Hiller FC. Postoperative evaluation of sleep apnea after uvulopalatopharyngoplasty. Laryngoscope 1986;96:738-41.

11 Katsantonis GP, Walsh JK, Schweitzer PK, Friedman WH. Further evaluation of uvulopalatopharyngoplasty in the treatment of obstructive sleep apnea syndrome. Otolaryngol Head Neck Surg 1985;93: 
244-54.

12 Caldarelli DD, Cartwright R, Lilie JK. Severity of sleep apnea as a predictor of successful treatment by palatopharyngoplasty. Laryngoscope 1986;96:945-7.

13 Borowiecki B de B, Kukwa AA, Blanks RHI. Indications for palatopharyngoplasty. Arch Otolaryngol 1985;111: 659-63.

14 Sullivan CE, Issa FG, Berthon-Jones M, Eves L. Reversal of obstructive sleep apnoea by continuous positive airways pressure applied through the nares. Lancet 1981;i:862-5.

15 Frith RW, Cant BR. Severe obstructive sleep apnoea treated with long term nasal continuous positive airways pressure. Thorax 1985;40:45-50.

16 Rechtschaffen A, Kales A, eds. A manual of standardized terminology, techniques and scoring systems for sleep stages of human subjects. Los Angeles: University of California, Brain Information Service/Brain Research Institute, 1968.

17 Guilleminault C, Dement WC, eds. Sleep apnea syndromes. New York: Liss, 1978.
18 Gordon ASD, Giles ML, Harding DA, Morton RP. $\stackrel{\times}{.}$ Surgery of snoring. J Laryngol Otol 1986;100:1263-7. $\overline{\overline{\bar{C}}}$

19 Ray CS, Sue DY, Bray G, Hansen JE, Wassermann K. Effects of obesity on respiratory function. $A m \operatorname{Rev}$ Respir Dis 1983;128:501-6.

20 Guilleminault C, Simmons FB, Motta J, et al. Obstructive sleep apnea syndrome and tracheostomy. Long $\underset{\mathbb{Q}}{\mathbb{Q}}$ term follow-up experience. Arch Intern Med 1981;141: ڤి 985-8.

21 Conway WA, Victor LD, Magilligan DJ, Fujita S, Zorick $\vec{\circ}$ FJ, Roth T. Adverse effects of tracheostomy for sleep apnea. JAMA 1981;246:347-50.

22 Simmons FB, Guilleminault C, Dement WC, Tilkian AG, Hill M. Surgical management of airways obstruc- $\vec{x}$ tion during sleep. Laryngoscope 1976;87:326-38.

23 Smith PL, Gold AR, Meyers DA, Haponik EF, Bleecker ER. Weight loss in mildly to moderately obese patients $\omega$ with obstructive sleep apnea. Ann Intern Med 1985;103: ㅇ $850-5$.

24 Raymond CA. Popular, yes, but jury still out on apnea surgery. JAMA 1986;256:439-41. 